\title{
Geography - Problem Solving Competencies for Societal Concerns
}

\section{Rita Schneider-Sliwa, Hartmut Leser, Basel}

\section{Key qualifications of geographers and career opportunities}

Geographers are called upon in situations where spatially defined phenomena have to be dealt with. They are asked to study phenomena that have a specific location, occur in a specific area and directly or indirectly induce spatial effects, and that have underlying regularities. To put it simply, geographers analyze spatial processes, functional and structural patterns, as well as investigate the spatial and temporal dynamics thereof, presenting the results in analog and digital maps.

Due to the diversity of geographical problems, it is difficult to foresee in which field students of geography will eventually work. Consequently, aspiring geographers have to acquire a broadly based problem solving competence, as well as master a series of key qualifications. In his article «Geographische Problemlösungen für die Praxis (Geographic Solutions in Practice), T. Mosimann (1996: 197 ff.) listed the following key qualifications (Fig. 1):

- the ability to recognize complex interrelationships of the human-environmental system

- the ability to analyze landscape structures and landscape ecological processes in situ and to present them appropriately

- the mastery of relevant qualitative and quantitative methods

- the ability to combine and adapt methods, as well as develop new methods

- the ability to process and present spatially referenced data by means of analogous and digital maps and models

- the ability to mobilize expert knowledge, as well as lead and moderate teams of experts.

Although these qualifications do appear to be rather general, they receive an increasing relevance as a result of their relationship to spatial or geographical fields of investigation. The broad spectrum of qualifications that geographers acquire during their studies ensures that they have a solid basis with which to cope with the unforeseeable expectations on their future profession. Further, they have an advantage over competitors in the field. Geographers can be employed for a multitude of tasks because:

- they have a broad spectrum of qualifications and geographical problem solving competencies
- they are, in particular, trained to offer an integrative perspective of the world today, taking both the natural and social sciences into consideration. It is not without reason that landscape ecological and human-ecological approaches have proven to be particularly suitable theoretical foundations for the broad range of working methods of geographers.

The qualifications of geographers allow them to give expert advice on the ecological, social and economic compatibility of current spatial developments. Thus, the classical fields of professional geographers can be summarized as environmental and social monitoring.

Social or environmental monitoring in terms of geography is the tracking down, and even more so, the permanent recording and documentation of current developments in the social, economic and ecological environment, irrelevant of whether these pertain to real or simulated situations. Social and environmental monitoring allow for the continuous registration and recording of political, administrative, economic and demographic changes and developments in landscape ecosystems, the results of which are included in longterm investigations. These investigations serve as a basis for assessment and decision-making in planning and structural policy, in environmental, economic and social policy. The «longitudinal sections» drawn of the current social and economic status, as well as of the environmental space serve on the one hand as a comparative gauge for future development, and on the other as a standard for the utilisation and further development of existing opportunities.

To this day, many of these developments remain poorly quantified (e.g. social polarisation, environmental damage), due to

- their novelty, their complex interplay and their intensity. These processes were dealt with inadequately at both the theoretical and empirical levels. These are shortcomings noticeable both in research and applications;

- the lack of basic data at the regional level. The documentation of these new processes and the analysis of their dynamics over a period of time is severely limited.

Thus it is important that a geographer can

- collect structural data systematically

- present current spatially referenced social, economic and environmental structural patterns and processes

- explain the relations between processes

- derive trends and interpret these. 
Monitoring should be seen as a long-term activity if it is to be effective. Thus, it is necessary to always work with data which is up-to-date or that can be updated. This is only possible with databases and Geographical Information Systems (GIS). Standardised procedures are necessary to carry out, for example, comparative regional geographic studies of socio-economic and eco-geographical processes, or to forecast trends in problem areas, such as the increase or decrease of development gaps.

New needs of society result from developments such as globalisation, liberalisation, and the decoupling of economic, social and societal policy, or may result from the technologically induced change of urban and landscape ecosystems. Society would like to, and indeed should understand these new structures better in order to be able to control them. To be able to do this, these structures and developments need to be monitored. Just how important the recording and investigation of current processes is, can be seen in the work of research institutes that concentrate on continual spatial surveillance. In many cases, the mission of these institutes is to analyse and document current and future spatial developments, thereby creating a statistical basis for spatial and urban development, as well as regional policy.

The importance of social and environmental monitoring may be seen in the steadily increasing interest that disciplines, in particular within the natural sciences, economics, and social sciences are showing in Geographic Information Systems (GIS). By using these tools, these study fields hope to be able to draw on the geographical understanding of the complex reality of environment, be it natural or socio-economic. Even though geographic solutions, as described above, are broadly speaking not automatically achieved by using a technical tool such as GIS, the developments in related scientific fields are to be taken note of. It seems that these fields of study are using GIS in order to better address

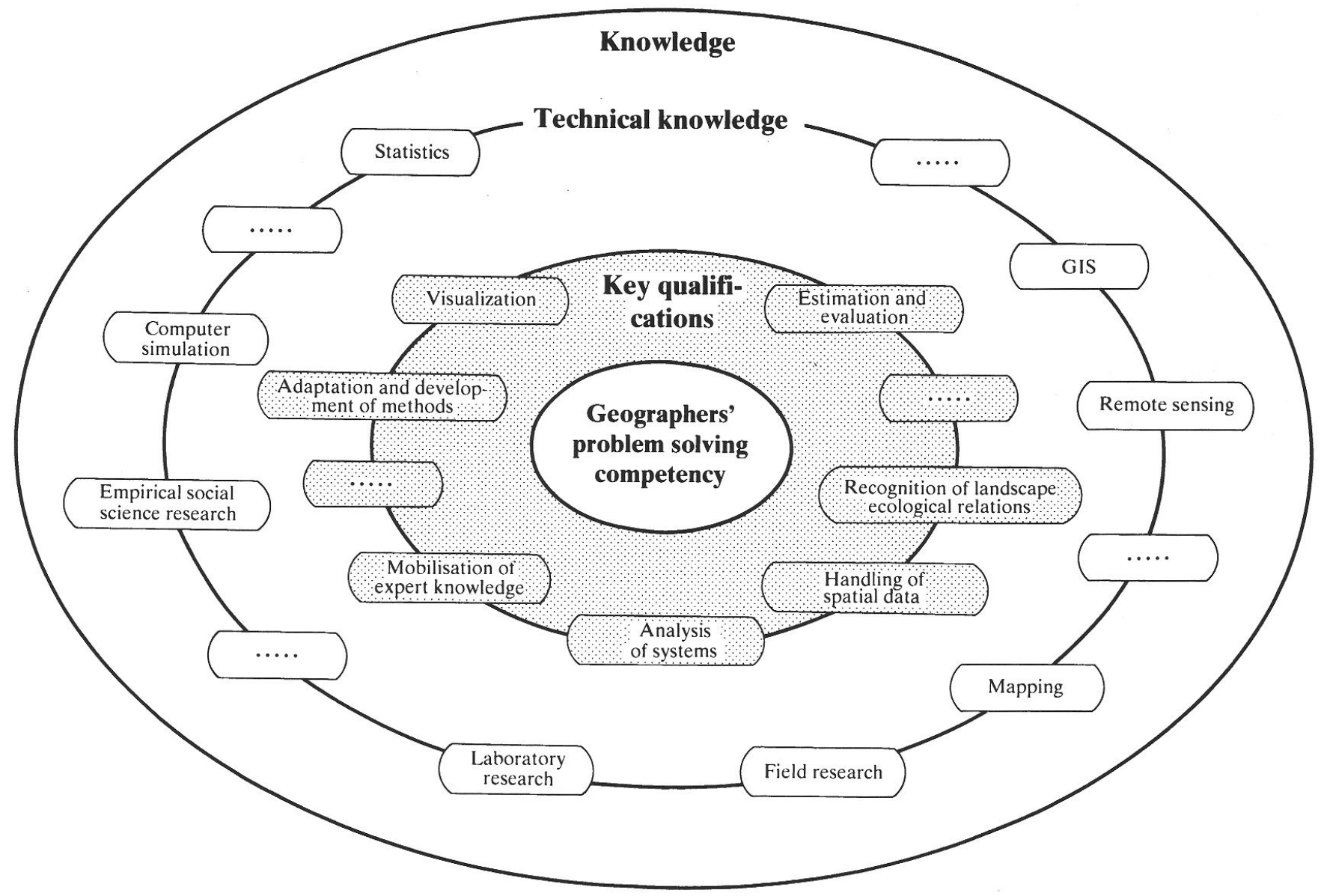

Fig. 1: Problem solving competence of geographers - key qualifications Geographische Problemlösungskompetenz - Schlüsselqualifikationen Compétence géographique en solution des problèmes - qualifications clés Source: Mosimann (1996) 
their own specific lines of question to the market. Thus, the increased interest in GIS has to be understood as serious competition for professional geographers.

The field of geography traditionally focuses on key qualifications that allow the successful pursuance of environmental and social monitoring. During the course of geographic studies the following skills are mediated:

- an understanding of the interplay between natural and socio-economic systems that are subject to an integrative, complex geographical perspective;

- an understanding for the varying perspectives and interpretations of spatial developments that result from different levels of observation of geographical reality in spatial and temporal scales (so-called geographical dimensions);

- technical skills, such as:

- proficiency in Geographic Information Systems for the retrieval, interpretation and presentation of data according to different perspectives from both physical and human geography

- experience with computer-aided cartography

- knowledge of calculation programmes for graphics and tables

- proficiency in advanced statistical analysis;

- content-specific methodological competence (against the background of a wide spectrum of specialised regional geographical knowledge);

- an understanding for the need of transdisciplinary approaches: the requirement to compliment the study of geography with relevant minor subjects (such as biology, chemistry, geo-sciences, law, regional planning and economics) must be seen in connection with the technical and methodological requirements of the subfields of geography. Due to the complexity of environmental reality, geography students are expected to gain competence in their own and other fields of study;

- additional qualifications resulting from practical experience: trainee positions in the professional world during the students' study period improve their qualifications. Students are either placed in institutes dealing with regional and environmental research or planning.

Major professional geographers' associations such as the German Association for Applied Geography (Deutscher Verband für Angewandte Geographie/ DVAG) and the Swiss Association of Applied Geography (Schweizerische Gesellschaft für Angewandte Geographie/SGAG) monitor the key qualifications of university graduates and the profiles of professional geographers in the light of their expected ability to deal with spatial problems of relevance to society. The main professional fields of geographers allow insight into the qualifications expected after a uni- versity education (DVAG 1996; e.g. 29-33, 38, 47ff., 54-57):

Regional planning and implementation involves not only specialized planning and implementation of effective spatial measures, but also inter-departmental planning in order to suitably integrate and co-ordinate all functions and needs of a planning area. The professional opportunities in this field primarily require an economic, socio-economic or regional planning background, but good knowledge of environmental and landscape sciences is of benefit. The following professional sectors belong to this category:

- urban, regional and national planning (departmental or sector planning)

- urban and regional research

- spatial development planning

- economic and structural policy including labour market research and economic development

- transport and mobility research including traffic planning and transport policy, as well as tourism

- telecommunications

- market and location analysis including real estate and residential business, and residential policy.

Environmental and landscape activities also include spatially relevant sector planning and trans-departmental regional planning, in this case focussing on environmental protection and nature conservation, as well as on precautionary environmental measures, partially in connection with supply and waste disposal. This field extends to include environmental law and appropriate planning procedures. Besides the division into sectoral and integrative planning, one also finds within nature conservation landscape planning that focuses on coordination and integration. The latter runs parallel to development planning, land utilisation and regional planning, unlike these concentrating on undeveloped and/or open spaces. Of course, these fields of work require primarily a background in physical geography and landscape ecology, but in addition good knowledge in legal and socio-economic matters is a necessity. The following professional areas belong to this category:

- environmental and landscape planning

- environmental protection and nature conservation

- landscape and environmental impact assessments

- ecological risk analyses

- soil conservation and the planning of sustainable land-use

- recording and rehabilitation of toxic waste deposits

- mapping of biotopes and environmental conservation planning

- geo-ecosystem research and ecological management

- environmental economics

- environmental law. 
Information and documentation regarding the implementation and evaluation of planning measures. Different methods are used to collect, prepare and present empirical data on spatial developments. These include those used by state institutes for statistics and market research in their surveys, as well as those for data analysis using remote sensing and aerial photography. Specific professional groups depend on the data collected in the above manner, as well as on that found in databases, libraries and archives or via geographical information systems and information services. The following professional areas belong to this group:

- press and publishing, as well as other media (television, radio, film)

- public relation departments of administration, associations and other related groups

- public statistic offices

- prognostic market research and information services

- commercial remote sensing

- cartography using computer-aided cartography

- geo-computing and geo-statistics using GIS.

Universities, schools and educational facilities. This group, made up of institutions of research, education and training is difficult to categorize due to its broad and manifold links to politics, planning, administration, the media and other public facilities, as well as to various professional groups. Geographical research concentrates predominantly on spatial aspects of humanenvironment relationships. In all of the subfields of geography, research plays an important role, the focus however increasingly moving towards interdisciplinary and trans-disciplinary cooperation. Research is increasingly becoming more market oriented or contract based. Research is part of the education of professional geographers, teachers and young scientists. Practical application always played a role; what is new is the function as service provider to the economy and public administration - a role, however, that should neither lead to the neglect of basic research, nor to a rival situation with its own graduates. The main fields of activity of geography in universities are

- basic research in all subfields of geography, however, with the aim to build up a centre of competence specialising in a particular theme, if possible in collaboration with other scientific fields

- development of guidelines on the training of research- ers, professional geographers and teachers

- contributions towards adult education and continuing education (as a form of public relations).

Of increasing importance is the role of the geographic institute as the initiator of regional structural change through its cooperation with industry, commerce and public administration, as the cultivator of spin-off companies founded by university graduates, and as the promoter of potential technology transfer.
Schools encompass a broad field of activity, where key qualifications of geographers can be applied. Geography education can heighten the awareness of citizens to the problems in their surroundings, the environment, and society. Thus, the goals of school geography reflect not only those of university geography, but they are based on the state of the art of geography as a science. As school geography is more than simply the transfer of «knowledge about the earth», it is not surprising that spatially-related competence is part of the school curriculum. For this reason, the teaching of geography at school-level aims to promote the following:

- the ability to think and act in spatial structures

- the ability to deal with ecological, economic, social and society-specific or political processes in landscape and urban ecosystems

- the knowledge of spatial laws and models at different levels of dimension of geographical perspective - from the local to the international level of functional relations

- the imparting of geographic and geological knowledge based on scientific systems theory and modern didactical practice.

Summary: the job specifications for professional geographers who have a good chance in today's labour market presuppose the above mentioned competencies and qualifications. In the professional world today, however, geographers have to increasingly compete with applicants from related fields, who have accumulated qualifications that are very similar to the key qualifications of geographers. However, the clear difference between applicants from other fields and geographers is that the problem solving competency and the key qualifications of geographers are more broadly based: the geographer's scientific competence is marked by an integrative natural and social science approach and methodological competencies focused on spatial structures and developments. These are the abilities that distinguish professional geographers from graduates of other fields of study!

\section{Training for problem solving competency}

Knowledge is a product and scientific operations are competitive. Thus, in today's society, a scientific discipline has to produce socially relevant achievements and competencies to be able to hold its own against the competition from other disciplines. It is equally important that geography is able to recognise and make use of those gaps in the market that pertain to the solving of social and environmental problems.

Geography researches, teaches and works in a world largely confronted by geographical problems, i.e. problems with a spatial or spatio-functional dimension. 
Thus, the reference to space is a central element of problem solving competence today. The difference to geography until the mid-sixties when «space» referred to «real» space only, is that today space refers to real areas and to cognitive and abstract spaces that in reality are behavioural fields. For both types of space, structures, functions and relationships are investigated. For this reason, geography may be referred to as the science of space, bestowing on it an advantage over related sciences. There is a need for this specialisation in space in all those fields where human and environmental systems are investigated. However, this need has not yet been seen as such by politicians and other decisionmakers. The investigation of human and environmental systems should not only concentrate on the interplay of biological, chemical and physical functions, but also include economic and socio-spatial aspects. The current status of these systems should be known if they are to be used as a basis of comparison for future development, utilisation and consolidation of potential.

To be able to do the above, geographical problem solving strategies need to be implemented (by administration, parliaments and planners). The field of geography can offer the above, but geography has to be given the competence to do so. What is problem solving competency? - a problem-oriented and subject-specific way of thinking that allows for:

- the recognition of problems as such and for the detection of their structures

- the choice of the most suitable approach for the situation

- the combination of skills necessary to develop an appropriate method

- the ensurance that within an acceptable time span

- the problem is recognised and presented in an appropriate spatial and temporal resolution, and that

- various solutions are proposed which can serve as the basis for decisions at the political, administrative, economic, environmental, social and/or planning levels.

In order to analyse problems and find solutions, geography is endowed with specific strengths. Only geography is able to offer strategies that reflect the complexity of a problem area, and take different dimensions into consideration that are spatially anchored. In a society based on the division of labour that sees the sciences as a further economic sector and expects scientific graduates to be competitive, it is important that the specific problem solving competency of geographers is emphasized.

The performance of geography and geographers is the result of the combination of cognitive and methodological skills, based on an integrative understanding of empiricism and theory. The well-trained geographer has the following competencies:

- Cognitive competency

- Specialised competency

- Methodological competency

- Social competency - and the closely associated

- Communicative competency.

Cognitive competency is the product of the fundamental activity of scientific and applied geography, to investigate relations in human-environmental-spatial systems as processes influenced or controlled by human beings. Other disciplines have similar areas of interest, however, without including the dimension of geographic space.

Specialized competency is the product of knowledge based on geography-specific contents and interests that focus on the characteristics and traits of human-environmental-spatial systems. The ability to apply specialized knowledge in an interdisciplinary and coherent manner to interdisciplinary socio-economic and ecological problems is a further characteristic of this form of competency.

The methodological competency of geographers has two components: a specialized part, and an interdisciplinary part. The geographer should be able to recognize and master methods from within his or her field and related sciences and be able to employ these in an interdisciplinary context. At the same time, attention has to be paid to the continuous change and improvements in methodology and technology. The specific qualification and competency of a geographer draws upon the ability to be able to acquire specialised knowledge by means of modern methods, to employ that knowledge within project or problem situations, and to enhance that knowledge by means of deduction and with other results and methods. The German Association for Professional Geographers (DVAG 1996: 104-108) divides the general key qualifications relevant for professional positions into three categories: the ability to apply

- methods suitable for solving problems and dealing with tasks geographers are confronted with at the workplace

- methods suitable for the investigation and utilisation of information (data collection and editing, data management in the face of a flood of data)

- methods of transferring information between people and/or groups involved in solving the current problem, or affected by it.

The specific methodological competency of geographers focuses on empirical work using statistics, cartography and remote sensing as exercised in the natural and social sciences, as well as in economics. Many of these methods today are, however, only applied in connection with GIS. In brief: 
- Empirical work: to be acquainted with and be able to implement methods necessary in surveys, such as recording, census taking, mapping, or in situ interviewing, as well as to be able to store the raw data in databases;

- Statistics: to be acquainted with and be able to implement approaches suitable for the processing of spatially related primary data and official statistical material (secondary data), as well as to be able to store the results in databases;

- Cartography: to be acquainted with and be able to implement techniques suitable for the management and presentation of localised and spatially differentiated information;

- Remote sensing: to be acquainted with and be able to implement techniques suitable for the analysis and interpretation of aerial and satellite images as primary and complementary sources of information and as means of presenting spatial information;

- Geographic information systems (GIS): to be acquainted with and be able to set up and use GIS and related databases as a means of:

- Presenting and analyzing data according to the principle of information layers

- Appropriately adjusting results gathered by means of the techniques described above.

Social competency is a behavioural qualification, and as such is linked to communicative competency. It has to do with the acquisition of skills that contribute towards creating a smooth working process for all parties involved in a common project. Amongst these are skills and characteristics such as leadership qualities, implementation skills, the ability to intervene and criticize, as well as skills that allow one to act on one's own initiative, be responsible, creative, innovative, cooperative and a team player.

Communicative competency should be both discursive and reflective. It refers to the ability to recognize, comprehend and understand, interpret and process complicated events intellectually. The information, relationships, and conclusions processed in the manner described above need to be passed on precisely in a manner appropriate for the situation, be it verbally or graphically, or in cartographic or mathematical-statistical form.

It is a matter of course, that the competence to offer solution strategies for social and environmental problems also includes social competency. Social competency is not so much the acquisition of theories that are out of touch with reality, but the ability to understand current problems that reflect the general search for the meaning of life. This type of competency also includes the ability to be aware of the personal, collective and political consequences of such problems. Recent def- initions of geographical competency for developing problem solving strategies emphasise the importance of the cognitive, methodological-technical and discursive-reflective aspects of this skill (BLOTEVOGEL 1996).

\section{The place of geographers in the world of tomorrow - a summary}

The first parts of this article concentrated on the position that geography takes in the canon of sciences, and on the services it can and could offer in today's society. Emphasis was placed on the primary performance strength of geography today - its traditionally integrative and interrelated approach. Despite the general talk about transdisciplinary, multidisciplinary and interdisciplinary approaches, very few sciences actually practise these problem solving forms. The need to do so with the current work on interrelated systems and coherence is greater than ever before.

It is interesting to note that the interrelated and systematic approach traditionally associated with geography was not easily introduced into other sciences. As early as the 1920s, the physicist Werner HeISENBERG postulated that the world was not a collection of single objects, but that the different parts of the whole were connected by a fabric of relations. He added that classical means of explanation were limited in their ability to describe all of the relations within the whole to the same degree of satisfaction (HEISENBERG 1987: 113).

The ability to focus on the interrelated aspects of systems that include human, societal, economic and environmental activity is the ability to observe a situation from a higher level - a meta-level. It is this ability which enables geographers to approach problems in today's society more completely, and thus also more appropriately than professionals from other fields. Geographers are thus able to better understand environmental systems, and to analyse them more precisely and forecast changes more realistically. The same quality of results cannot be reached through the sole analysis of individual parts of the system. To formulate it more casually: intellectual diversity in geography is the basis for the ability to analyse a diverse range of problems in society. The paradigm accumulation that the field of geography has experienced to-date at the conceptional level underlines the above. Not only has this accumulation led to a noticeably expanded understanding of spatial systems in space, and thus to an improvement of the cognitive competency of geographers, it has also led to a marked expansion of the methodological skills.

What is the situation of professional geographers in 
the working world? Generally, professional geographers find employment because due to their knowledge of a broad spectrum of methods, they can work on a great variety of problems. However, more often than not, neither the employer nor the employee are aware that these abilities are the result of the integrative, interrelated approach and the notable cognitive competencies geographers develop during their studies. Decisive for the selection of a professional geographer over other candidates from related subjects are often the obvious or measurable skills, i.e. his or her considerable knowledge of technical approaches. Particular methodological skills characterize geographers in today's professional world, such as the versed operation and application of GIS, statistical programmes, digital maps, remote sensing data, laboratory and field testing techniques. It is these skills that increase the chances that a geographer will get a position in preference to a candidate from a related discipline. It should be noted that technical skills alone do not make a geographer; it is rather their mental ability to recognize the inter-relatedness of a problem, to design relevant specific means of analysis and to anticipate developments and alternative solutions, before actually physically dealing with the situation.

The world and society today find themselves to a greater degree than ever before in a state of intensive ecological, economic and political change. It would be presumptuous for geography to claim that its academic programmes have been defined in such a manner that they will fully be able to take into account all future developments in society and the world.

The main problem that geography is faced with is the continual change of the world itself as it is the world and change that are the focus of the field of geography. In this respect, other sciences have it easier - in many cases, the subjects of investigation are constant and only need to be dealt with according to the current dominant perspective of the situation. Within the field of geography both the frame of observation and the object of investigation undergo continual change. Consequently, unlike other fields of study, the objectives set for geography are somehow different. Said simply geographers are expected to be able to do more.

\section{Research - Swiss geographical institutes as part of the social «market»}

How research and education in Swiss geography are dealt with against this setting are the main subjects of this thematic issue and the articles that follow. Swiss universities are experiencing the redefinition of responsibilities as part of a general university administration reform. Individual institutions are expected to show more self-initiative and also to be more self-responsible. At the same time the administrative executive is under pressure to quantify the performance and «products» (graduates, services, quality of syllabus) of publicly financed educational and research establishments. With this development, science is forced to accommodate stricter economic criteria of evaluation in the sense of performance capacity, as well as accountability to questions of cost and use for society. Under the umbrella of New Public Management, publicly financed establishments are thus expected to deliver proof of their performance to society according to set criteria here the focus being on justifiable research.

The geographical institutes are responding to the challenge by adapting themselves to the new economic framework increasingly defined by politics, the economy and society. Within the field of science, a permanent, future-oriented geography means inevitably that the needs of today's society regarding research «products» and economic viability of graduates have to be met. Specifically, the institutes must:

- redefine their fields of responsibilities regarding educational quality

- conduct more basic research aimed at practical implementation (e.g. planning decisions)

- concentrate on central fields of specialization, to become aware again of their own qualities and resources

- focus on their very own «investment capital», i.e. geography's natural market opening. This in return means:

- paying attention to integrative approaches

- encouraging methodological diversity

- upholding the spatial reference

- integrating geographical concepts and geographical methodological knowledge into other fields of study and areas of activity.

In this issue we will address how the different geography departments and institutes in Switzerland meet this challenge.

\section{References}

Blotevogel, H.H. (1996): Aufgaben und Probleme der Regionalen Geographie heute - Überlegungen zur Theorie der Landes- und Länderkunde anlässlich des Gründungskonzeptes des Instituts für Länderkunde, Leipzig. - In: Berichte zur deutschen Landeskunde 70: 11-40.

Deutscher Verband für Angewandte Geographie (DVAG) (1996): Geographen und ihr Markt. - Das geographische Seminar, Braunschweig: Westermann Schulbuchverlag: 1-141.

Heisenberg, W. (Hrsg.) (1987): Hans Christian Meiser. Ausgewählte Texte. - München: Goldmann: 1-127. 
Mosimann,T.(1996): Geographische Problemlösungen für die Praxis - marktfähig für die Zukunft? - In: 50. Deutscher Geographentag Potsdam 1995, Tagungsbericht und wissenschaftliche Abhandlungen, Bd. 4, Franz Steiner Verlag: 192-203.

SCHLÜTER, O. (1919): Die Stellung der Geographie des Menschen in der erdkundlichen Wissenschaft. - In: Geographische Abende im Zentralinstitut für Erziehung und Unterricht 5, Berlin: 1-34.

Prof. Dr. phil Rita Schneider-Sliwa, Abteilung Humangeographie/Stadt- und Regionalforschung, Prof. Dr. rer.nat.Dr.h.c. Hartmut Leser,Abteilung Physiogeographie und Landschaftsökologie, Geographisches Institut, Universität Basel, Klingelbergstrasse 27, CH-4056 Basel.

\section{Internet addresses}

Departement Geographie: http://www.unibas.ch/geo/

Physiogeographie und Landschaftsökologie:

http://www.physiogeo.unibas.ch

Humangeographie/Stadt- und Regionalforschung:

http://www.humgeo.unibas.ch 